Article

\title{
3D Microporous Scaffolds Manufactured via Combination of Fused Filament Fabrication and Direct Laser Writing Ablation
}

\author{
Mangirdas Malinauskas ${ }^{1}$, , Sima Rekštytė ${ }^{1}$, Laurynas Lukoševičius ${ }^{1}$, Simas Butkus ${ }^{1}$, \\ Evaldas Balčiūnas $^{2}$, Milda Pečiukaitytè ${ }^{2}$, Daiva Baltriukienè ${ }^{2}$, Virginija Bukelskienè ${ }^{2}$, \\ Arūnas Butkevičius ${ }^{1}$, Povilas Kucevičius ${ }^{1}$, Vygandas Rutkūnas ${ }^{3}$ and Saulius Juodkazis ${ }^{4,5,6, *}$ \\ ${ }^{1}$ Laser Research Center, Department of Quantum Electronics, Faculty of Physics, Vilnius University, \\ Saulètekio Ave. 10, LT-10223 Vilnius, Lithuania; E-Mails: sima.rekstyte@ gmail.com (S.R.); \\ laurynaslu@yahoo.com (L.L.); simas.butkus1@gmail.com (S.B.); arunasb@gmail.com (A.B.); \\ povilas@dinovus.lt (P.K.) \\ 2 Department of Biological Models, Institute of Biochemistry, Vilnius University, Mokslininkụ Str. 12, \\ LT-08662 Vilnius, Lithuania; E-Mails: evaldas89@gmail.com (E.B.); milda.peciukaityte@gmail.com \\ (M.P.); daiva.baltriukiene@gmail.com (D.B.); virginija.bukelskiene@gmail.com (V.B.) \\ ${ }^{3}$ Institute of Odontology, Faculty of Medicine, Vilnius University, Žalgirio Str. 115, LT-08217 Vilnius, \\ Lithuania; E-Mail: vygandasr@gmail.com \\ ${ }^{4}$ Center for Micro-Photonics, Faculty of Science, Engineering and Technology, Swinburne University \\ of Technology, Hawthorn, VIC 3122, Australia \\ ${ }^{5}$ Department of Semiconductor Physics, Vilnius University, Saulètekio Ave. 10, LT-10223 Vilnius, \\ Lithuania \\ ${ }^{6}$ Melbourne Center for Nanofabrication, Australian National Fabrication Facility, 151 Wellington \\ Road, Clayton, VIC 3168, Australia
}

* Authors to whom correspondence should be addressed; E-Mails: mangirdas.malinauskas@ @ff.vu.lt (M.M.); sjuodkazis@swin.edu.au (S.J.); Tel.: +370-6000-2843 (M.M.); +61-3-9214-8718 (S.J.).

External Editor: Maria Farsari

Received: 30 July 2014; in revised form: 24 September 2014 / Accepted: 25 September 2014 / Published: 30 September 2014

Abstract: A 3D printing fused filament fabrication (FFF) approach has been implemented
for the creation of microstructures having an internal 3D microstructure geometry. These
objects were produced without any sacrificial structures or additional support materials, just
by precisely tuning the nozzle heating, fan cooling and translation velocity parameters. The
manufactured microporous structures out of polylactic acid (PLA) had fully controllable 
porosity $(20 \%-60 \%)$ and consisted of desired volume pores $\left(\sim 0.056 \mu \mathrm{m}^{3}\right)$. The prepared scaffolds showed biocompatibility and were suitable for the primary stem cell growth. In addition, direct laser writing (DLW) ablation was employed to modify the surfaces of the PLA structures, drill holes, as well as shape the outer geometries of the created objects. The proposed combination of FFF printing with DLW offers successful fabrication of 3D microporous structures with functionalization capabilities, such as the modification of surfaces, the generation of grooves and microholes and cutting out precisely shaped structures (micro-arrows, micro-gears). The produced structures could serve as biomedical templates for cell culturing, as well as biodegradable implants for tissue engineering. The additional micro-architecture is important in connection with the cell types used for the intention of cell growing. Moreover, we show that surface roughness can be modified at the nanoscale by immersion into an acetone bath, thus increasing the hydrophilicity. The approach is not limited to biomedical applications, it could be employed for the manufacturing of bioresorbable 3D microfluidic and micromechanic structures.

Keywords: 3D printing; fused filament fabrication; femtosecond laser; direct laser writing; light filament; polylactic acid; biocompatible; 3D scaffold; stem cells; tissue engineering

\section{Introduction}

Additive manufacturing (AM) technologies are highly versatile and continuously growing in their width and depth of potential applications. For instance, laser-based additive manufacturing has experienced a continuous growth of $\sim 15 \%$ per year for a decade [1]. For comparison, currently, an immense $\sim 150 \%$ jump per year is seen for 3D printing based on thermal extrusion [2]. This empowers the industrialization of various techniques from scientific laboratory equipment to batch production facilities. Furthermore, it presents the convenience of having a prototyping device for personal daily use at home. It seems that it is just a matter of time (within five years or so) when we will have a metamorphosis of a common question in an office: instead of whether to print it in black and white or in colors on a paper sheet, it will turn to whether to printing it in 2D or 3D and out of what material. It is important to note that contrary to $2 \mathrm{D}$ objects, which are nothing more than just images carrying information, the 3D objects can offer real functions. In this meaning, special attention should be given: a 2D object can serve as a label (instruction) for a $3 \mathrm{D}$ object, which could be the component performing some process. For example, in tissue engineering, a $2.5 \mathrm{D}$ structure can serve as an environment for cell culturing in vitro, yet a 3D template (scaffold) is necessary to (re)create the tissue in vivo. In consideration, the work presented here aims at efficient manufacturing of 3D structures suitable for cell growth experiments and tissue engineering applications. Before going deeper into details, an overview of existing technologies and processable materials will be presented stressing their advantages and limitations. 
Direct laser writing (DLW)-based nonlinear lithography employing ultrashort pulses is unique in its 3D structuring capacity and flexibility for the choice of materials [3-5]. The technique does not require clean room facilities and provides well-defined features with great reproducibility suitable for applications in nanophotonics [6,7] and integrated microoptics [8,9]. Thus, it is not surprising that it has been employed for the creation of 3D micro-templates used for cell studies [10,11]. Of the various chemistries used for manufacturing, protein photo-crosslinking is of particular value in biological applications, yielding materials with high porosity, tunable elasticity and a diverse set of chemical and biochemical properties [12,13]. Recently highlighted in the literature, hyaluronic acid is processable by DLW, as well [14].

The application of DLW towards the fabrication, manipulation and assembly of 3D polymeric and biomolecular structures can be further enhanced by the use of optical tweezers in aqueous media [15]. Composite material structures of various geometries and periodicities are of great interest and already technologically realized [16,17]. Centimeter-scale sample scaffolds are already producible overnight [18,19], with the ability to incorporate living cells [20]. It is noteworthy that many of the laser cross-linkable materials are biocompatible in vivo have shown in ex vivo tests of implantation into rabbit tissues [21]. The latest studies show that hybrid materials are potentially applicable for high intensity optical and photonic applications [22]. To summarize, the only drawbacks of the technique are the relatively high cost of equipment and low fabrication throughput (unless active or passive beam shaping methods are employed [23,24], not discussed here). An example of 3D microstructures demonstrating the potential of the technique for the creation of interlaying complex interconnected patterns is shown in Figure 1.

Figure 1. SEM (scanning electron microscope) micrographs of composite material structures (combining several different materials) fabricated using direct laser writing (DLW). Different materials are represented by different colors and indicated in the pictures. (a) 2D scaffold for determination of the most suitable material (or their combination) for cell growth. (b) 3D scaffold showing the possibility to incorporate the second material structures (PEG-DA-700) in various positions (not only the surface, but also the inside) of the primary structure (SZ2080). (c) composite scaffold, of three different materials. (d) Two free-standing structures fabricated out of different materials connected with a freely moving ring fabricated out of the third material.
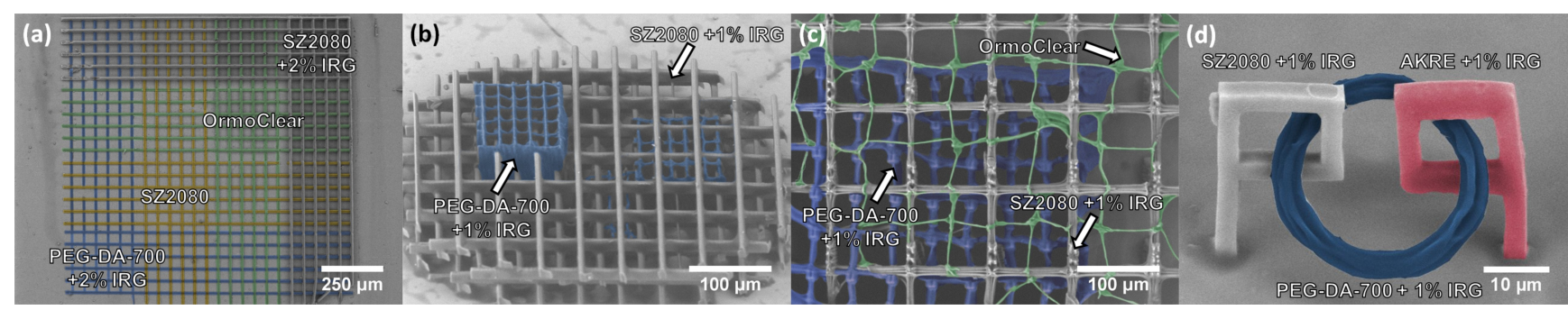

Employment of UV lasers preserves high-resolution spatially selective photo-crosslinking of various biomaterials; the photoinitiators must be inevitably used, commonly doping the processable material with $1 \mathrm{wt} \%$ [25]. Although the height of a single layer of a scaffold could be tuned, its capability of 3D fabrication becomes restricted, as the structure itself can be produced in a layer-by-layer 
manner only [26]. Recently, it was shown that in a sol-gel polymer SZ2080 and thermo-polymer polydimethylsiloxane, free-standing 3D structures can be obtained without the use of light absorbing photo-sensitizers by achieving structuring via controlled avalanche curing of the host material when a high intensity femtosecond pulse-induced nonlinear absorption is subsequently followed by an avalanche ionisation [27,28]. Other AM technologies, such as selective laser sintering/melting (SLS/SLM) [29,30] or selective electron beam melting (SEBM) [31,32], capacitates the processing of polymers, ceramics and metals. The skin-core strategy enables rapid fabrication of bulk type structures with great precision by precisely fabricating only the outer shells (contour scanning); the insides are filled due to the exposure to powerful defocused beams [33]. However, due to the clean room and vacuum requirements for the application of SEBM, this type of technology is difficult to integrate in production lines.

On the contrary, fused filament fabrication (FFF) 3D printing is an enabling technology providing innovation with unprecedented manufacturing flexibility and velocity. It is widely used to materialize CAD models into precise plastic objects. The method is very straightforward and efficient, employing tabletop devices, which are affordable for personal everyday use. It is becoming a standard tool for the manufacturing custom free-form elements consisting of sub-millimeter-sized features. Basically, its spatial resolution is restricted to the diameter of the extrusion nozzle (usually $\sim 0.4 \mathrm{~mm}$ in diameter), which is limited by the viscosity of the applied thermoplastic material. Macro-sized components with sub-millimeter precision can be designed and fabricated in a time-efficient manner, low material and equipment cost. 3D printing is also known for being an energy-efficient technology. In recent years, 3D printing moved from being an industrial prototyping and manufacturing process, as the technology has become more accessible to small laboratories, companies and even to individuals; indeed, simple table-top devices can now be acquired for under $\$ 1,000$. This opens up the technology to a much wider audience of users, and as the exponential adoption rate continues pace on all fronts, more and more systems, materials, applications, services and ancillaries are emerging. Bioresorbable materials, such as polycaprolactone (PCL), hyaluronic acid (HA), polylactic acid, their various mixtures and suchlike bioresorbable materials as polyglycols/acrylamides, are of great interest for bone and cartilage engineering [34,35]. Utilization of liquid surface tension and capillary forces can be employed for the contactless 3D printing on demand [36]. Currently contact 3D printing based on a thermal probe [37] is competing in terms of resolution and fabrication throughput with electron beam lithography (EBL).

PLA (polylactic acid) material and PLA derivatives as thermoplastics are well-known biodegradable substances that are widely used in micro-manufacturing via FFF [38], recently also in DLW ablation [39], as well as lithography [40]. Studies where high resolution 3D structures of polylactide-based materials structured via DLW lithography were applied as neural tissue engineering scaffolds have been reported. Neuroblastoma cell growth on such scaffolds shows the potential applications of this material for neuronal implants [41]. In principle, FFF allows the incorporation of nanoparticles in the material, which could add new properties and functionalities. For instance, it was recently demonstrated that nano-hydroxyapatite (nHA) incorporation does have an effect on cell proliferation, differentiation and extra cellular matrix (ECM) production; thus, it should be regarded as a bioactive component of dental bioengineered scaffolds, as it can be incorporated by doping into biomaterial hosts [42]. From a perspective point of view, this enables microprinting of nanomaterials, thus joining together micro- and nano-manufacturing capabilities [43]. 
A combination of laser-assisted additive and subtractive [44], as well as multiscale additive manufacturing employing UV and DLW lithography approaches [45,46] has been reported. Here is the first demonstration of combination of 3D printing (3DP) and direct laser writing-subtractive manufacturing (DLW-SM) for the fabrication of mesoscale structures (Mesoscale structures have dimensions of several millimeters with distinguishable and functional features down to the micrometer scale. Thus, the structures cannot be simply defined as microstructures), which are encountered in the most promising application field of these emerging technologies: biomedical and tissue engineering. The proposed hybrid manufacturing principle is depicted in Figure 2. In this study, a single step 3DP approach has been implemented for the creation of macrostructures having an internal 3D microstructure geometry. They were produced without any sacrificial structures or additional support materials. Further, DLW by ablation is used for the modification of surfaces, hole drilling, as well as outer geometry shaping of the whole objects and deliver surface textures on micro- and even down to the nano-scale. The photons were directed either by focusing the beam or by creating a femtosecond pulse generated filament [47], which was employed for DLW-SM processing. The proposed combination of FFF with DLW offers successful fabrication of 3D microporous structures with controlled pore sizes in approximately a $100-400 \mu \mathrm{m}$ range. The produced structures can serve as biomedical templates for cell culturing, as well as implants for tissue engineering.

Figure 2. The schematic principle of fabrication by combining fused filament fabrication (FFF) and DLW techniques: (a) the 3D structure is printed by melting and extruding a material through a nozzle; (b) secondary structuring is realized employing DLW; (c) the final PLA (polylactic acid) micro-scaffold.
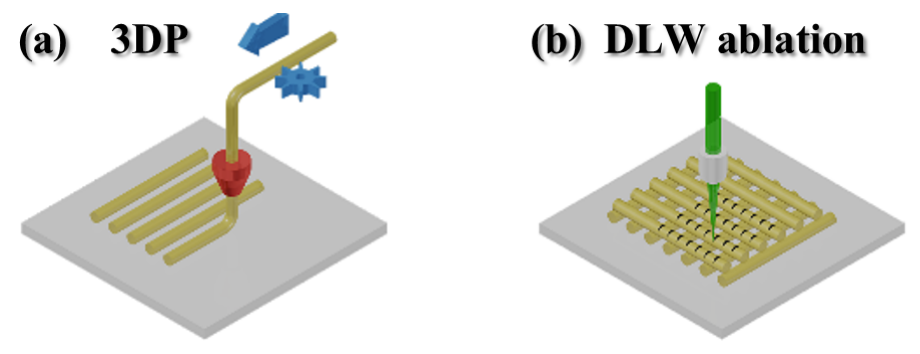

(c) PLA $\mu$-structure

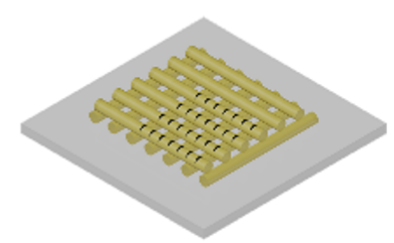

\section{Experimental Section}

\subsection{PLA Film Preparation and Surface Modifications}

In our experiments, a clear (pure) PLA material was used as obtained directly from "Ultimaker". For biological in vitro applications, pure PLA would be the most suitable due to a lack of intrinsic dyes, yet for clinical use, colored (green or blue) plastics are more convenient, because of a better visualization, which is important in a surgical environment. Thin PLA films were made by drop casting, heating to a temperature of $\sim 220{ }^{\circ} \mathrm{C}$ and pressing in between two glass slides. Etching in acetone was realized by simply submerging the PLA samples into an acetone bath and keeping them for a designated amount of time. The resulting surface modifications are shown in Figure 3. In all cases, SEM (scanning electron 
microscope) inspections were performed with a "Hitachi" TM-1000 (Tokyo, Japan) microscope without any conductive overlayer.

Figure 3. SEM images of a plain PLA surface (a) and after 1 and $8 \mathrm{~min}$ of immersion in acetone, $(\mathbf{b})$ and $(\mathbf{c})$, respectively. A woodpile structure after $1 \mathrm{~m}$ in acetone $(\mathbf{d})$.

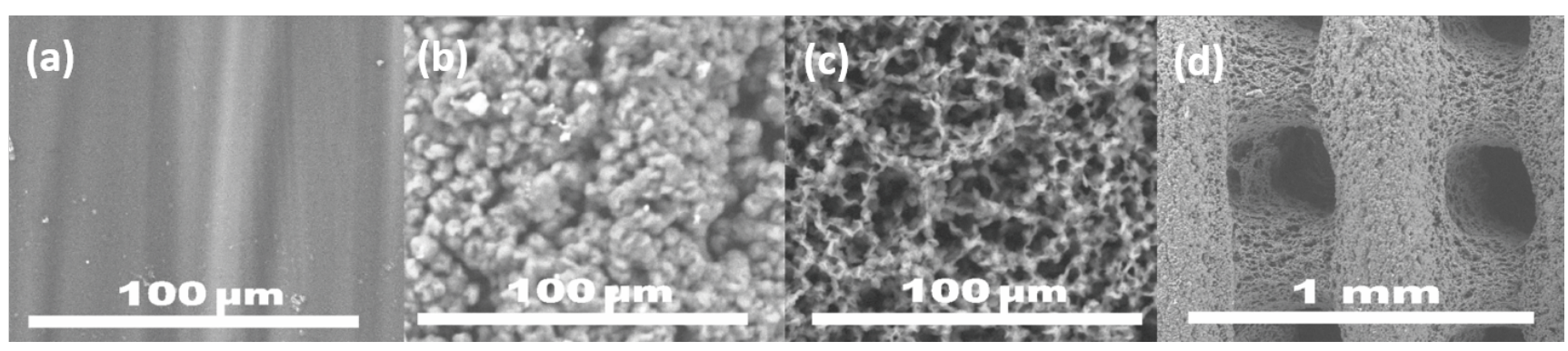

\subsection{D Printing via Fused Filament Fabrication}

In this work, we have employed the FFF 3D printer "Ultimaker" Original. It offers the highest single layer resolution of up to $20 \mu \mathrm{m}$, has a maximum build volume capacity of $23 \times 22.5 \times 20.5 \mathrm{~cm}^{3}$ and ensures nozzle position precision in the $X, Y$ and $Z$ directions of $12.5 / 12.5 / 5 \mu \mathrm{m}$, respectively. The original nozzle diameter is $400 \mu \mathrm{m}$ in diameter. The operating temperature was set to $200-220{ }^{\circ} \mathrm{C}$, and the pinpoint scanning velocity was set to $30 \mathrm{~mm} / \mathrm{s}$. The printing bed was of room temperature, and the cooling fan rate was set to 255 of its capacity (default value). The CAD models were created in the STereoLithography (STL) format and converted to g-code which was sent to the controller ("UltiController") via an Secure Digital (SD) memory card. The chosen objects for manufacturing were of woodpile geometry. Such architectures are exemplifications of a true structure having an internal 3D geometry with the capability to control the material-air volume fractions (filling ratio). The selected set of manufacturing parameters enabled a repeatable production of woodpiles having $700 \mu \mathrm{m}$ lateral and $400 \mu \mathrm{m}$ axial periodicities. The obtained line width and height were 300 and $200 \mu \mathrm{m}$, respectively. An SEM micrograph of a typical attained scaffold is shown in Figure 4. The width of an extruded log was always larger at the cross-sections, with a previously formed log oriented perpendicularly. This is caused by surface tension, viscosity and temperature gradients of the thermo-polymer, as it is cast onto a previously deposited log. The contact points between old and freshly extruded logs creates cooling points with surface tension pulling a liquid polymer by surface tension gradient towards colder regions [48]. This is a similar effect to a so-called "repolymerization" observed in DLW lithography, were overexposed regions seem to self-form repetitive structures in 1D [49] and 2D [50] manners. Despite that, such log pile micro-sieve structures having undercuts were successfully manufactured without any sacrificial substructures or support materials. This enables straightforward fabrication of 3D structures with the desired internal geometry without post-processing, such as acetone vapour polishing, developing or heating and mechanical removal of the undesired material. Since the formation of the final 3D structure is controlled by thermo-elastic flow and relaxation, an ambient temperature can influence fabrication; however, this can be easily solved by a simple enclosure of the manufactured sample. 
Figure 4. SEM micrographs of printed PLA-micro-log pile (woodpile) structure: (a) top view, lateral period $700 \mu \mathrm{m}$ and line widths of $300 \mu \mathrm{m}$ separated by $400 \mu \mathrm{m}$ gaps; (b) side view; the axial period was $400 \mu \mathrm{m}$ and line heights of $200 \mu \mathrm{m}$ separated by $200 \mu \mathrm{m}$ gaps.

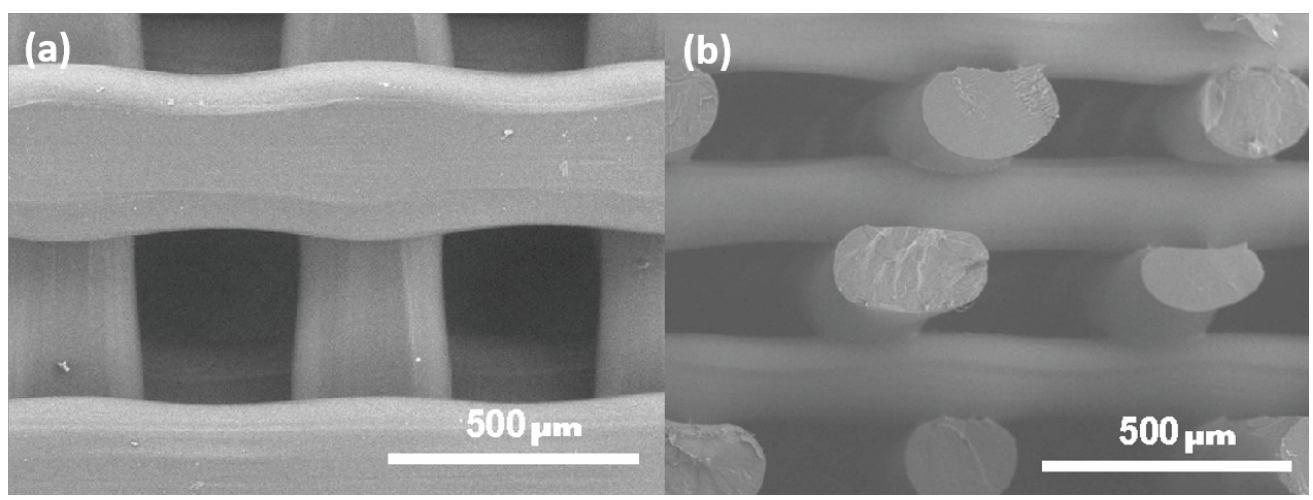

\subsection{Direct Laser Writing by Ablation}

All of the experiments were carried out using an Ytterbium doped Potassium-Gadolinium Tungstate (Yb:KGW) femtosecond amplified laser system "Pharos" (Light Conversion Ltd., Vilnius, Lithuania). The chosen parameters were as follows: an average optical power $P=5 \mathrm{~W}$, wavelength $\lambda=1030 \mathrm{~nm}$, temporal pulse width $\tau=300 \mathrm{fs}$, and the variable repetition rate $\nu$ was set to $25 \mathrm{kHz}$. Two different strategies of microprecision fabrication were employed: one employing DLW using sharp focusing conditions linear translation stages, and the other employing femtosecond pulsed generated light filaments (FPF) using loose focusing conditions (100 mm focal length by an f-theta lens) and a galvanometric scanner. The samples were translated using "Aerotech" linear motion stages or a two-axis galvanometric scanner (ScanLab Inc., Puchheim, Germany) was used for the beam deflection. All of the setup was controlled, and the process was automated by laser fabrication software SCA (Altechna Ltd., Vilnius, Lithuania). Figure 5 shows a schematic drawing of the light-matter interaction at sharp focusing and FPF cases, respectively. The laser beam was focused with an NA $=0.3$ and $10 \times$ magnification microscope objective lens (in a standard sharp focused beam fabrication) or an $100 \mathrm{~mm}$-theta lens (for filament assisted fabrication) on the PLA samples or covering with a water layer, respectively. For the conventional focused beam fabrication, the corresponding focused spot was $\sim 4 \mu \mathrm{m}$ in diameter, and the average laser power was adjusted depending on the specific exposure conditions and desired result. For the FPF, the processable sample was immersed in water, and the immersion depth was chosen to be approximately $0.5 \mathrm{~mm}$. Typical writing parameters for FPF were: focal spot diameter equal to $55 \mu \mathrm{m}$ and average laser power set to $5 \mathrm{~W}$. One can find more detailed information regarding light filament formation in liquids and its assisted rapid fabrication elsewhere [47,51]. In the case of focused beam fabrication, the sample was raster scanned in the $X-Y$ plane followed by change in $Z$ direction. For single holes drilling, it was just a translation along the $Z$-axis. In the case of FPF, only the $X$ - $Y$ plane was raster scanned, as the sample thickness was less than the formed filament length. Using FPF achieved nearly perfect repeatability of the fabricated complex structures. Strong ablation of the sample occurred after several consecutive pulses impinging on the same surface region. This resulted in the formation of a water-vapour channel and strong ablation, as well as efficient debris removal can commence; therefore, deviation in the expected laser path is negligible, even if rippling of the water layer occurs. 
Figure 5. Different laser beam focusing approaches, standard sharp focusing $v s$. liquid-assisted femtosecond pulsed generated light filaments (FPF): (a) focused beam on the surface of the transparent/opaque substrate; (b) focused beam in the bulk of the transparent material; (c) FPF in liquid-assisted rapid microfabrication of transparent/opaque targets.

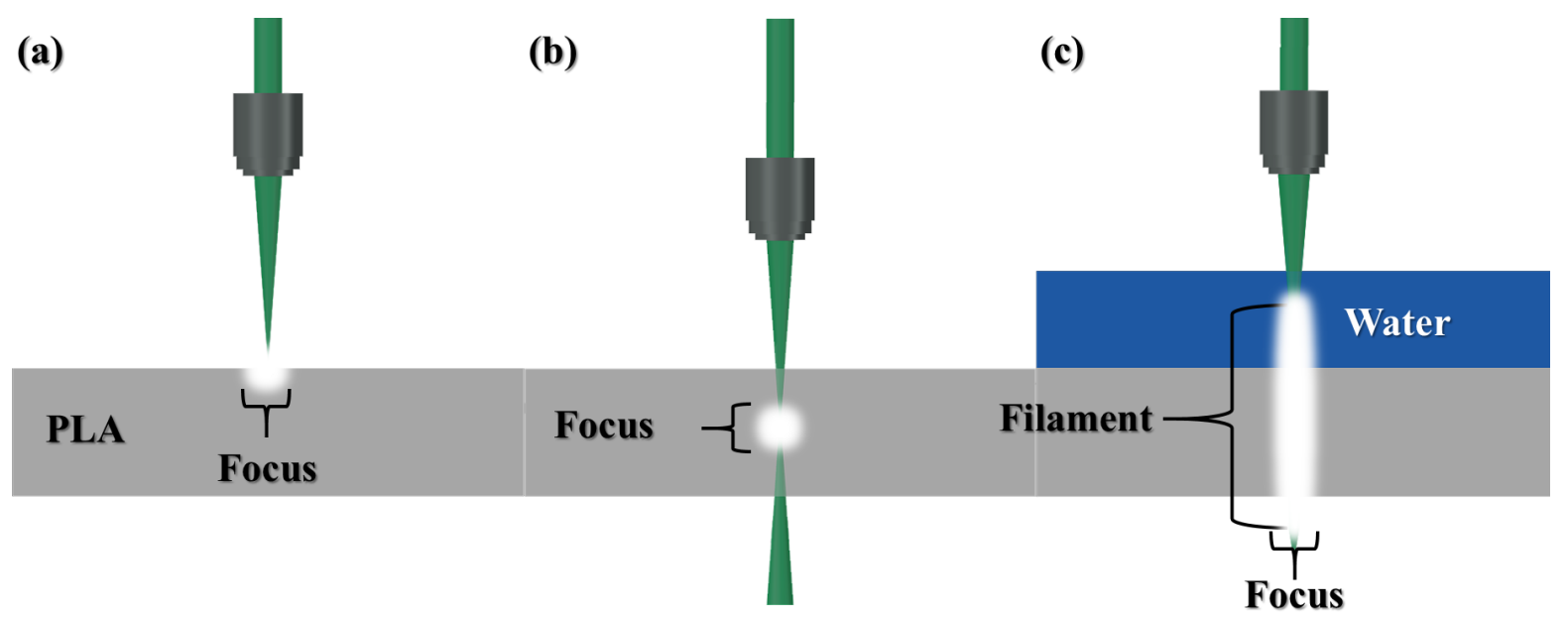

Initially, 200-400- $\mu \mathrm{m}$ sheets of PLA were microfabricated with a focused fs laser beam. Holes were made through the films by a percussion drilling with continuous translation of the focal position in the $Z$ direction (along the beam), as well as their surfaces were engraved by producing uniform straight line ridges. The dimensions of the holes were chosen to be within the range corresponding to a single mammalian cell size, Figures 6 and 7. Laser processing parameters were chosen as follows: average optical power $P=5-100 \mathrm{~mW}$, single pulse energy $E_{p}=0.2-4 \mu \mathrm{J}$ corresponding to $I=4.2-83 \mathrm{TW} / \mathrm{cm}^{2}$ (energy per pulse duration per focal spot [27]). The obtained surface modifications are shown in Figures 6 and 7. The groove width and depth increased along with the applied irradiation intensity, as well as debris scattering around the structured microfeatures was visible. Such surface modifications are attractive for surface area enlargement and amplified wetting properties, which are important for cell growth. An important feature of such structuring is the ability to precisely tune the dimensions of the produced micropatterns by simply adjusting the employed laser power/exposure dose.

For FPF fabrication, the focusing conditions were different; an f-theta lens was used and the average laser power increased to $5 \mathrm{~W}$. This corresponded to a dramatic increase of $E_{p}=200 \mu \mathrm{J}$, yet a comparative $I=75 \mathrm{TW} / \mathrm{cm}^{2}$ at a $55-\mu \mathrm{m}$ diameter of the focused beam spot (described in detail in [47]).

Figure 6. SEM micrographs of fabricated microgrooves in PLA employing a sharp focusing conditions: (a,b) sheet and (c,d) log-/wood-pile structure at different magnifications, front and side views, respectively.

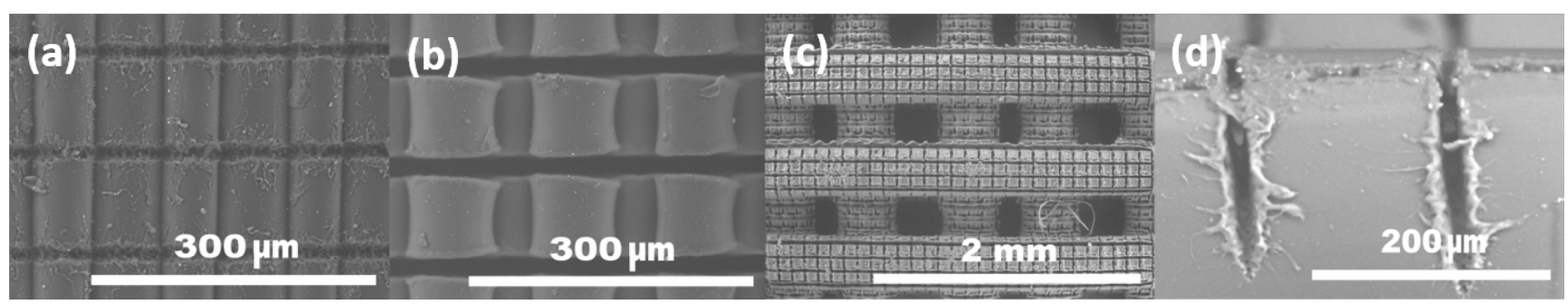


Figure 7. SEM micrographs of microholes drilled in PLA sheet (left) and woodpile (right): (a,c) using sharp focusing; (b,d) using FPF.

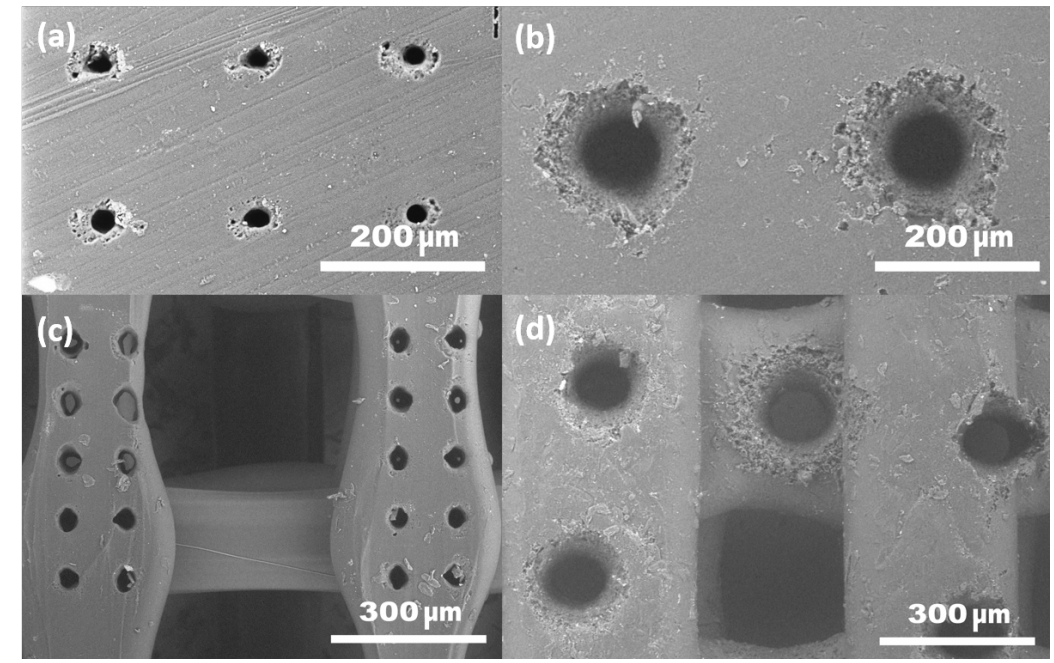

\subsection{Cell Culture Assay}

On the 3D-printed PLA scaffolds, rabbit skeletal muscle-derived myogenic cells were grown. Primary myogenic stem cells were derived from an adult rabbit thigh muscle: a small piece of tissue was minced and treated with a mixture of enzymes: $0.125 \%$ trypsin-EDTA (Ethylene Diamine Tetraacetic Acid) (Sigma-Aldrich, Munich, Germany), $1 \mathrm{mg} / \mathrm{mL}$ collagenase type V (Sigma-Aldrich) and $0.3 \mathrm{mg} / \mathrm{mL}$ hyaluronidase (Sigma-Aldrich). After the cell mass was washed with Iscove's modified Dulbecco medium (IMDM; Sigma-Aldrich) supplemented with 10\% fetal calf serum (FCS; Biological Industries, Kibbutz Beit-Haemek, Israel), the cells were counted and maintained in IMDM medium enriched with $10 \%$ of FCS. The cells were passaged twice a week using trypsin and EDTA mixture (Life Technologies, Waltham, MA, USA). For the printed PLA scaffold testing, the cells were used from Passages 20 to 40; the seeding density was 60,000 cells $/ \mathrm{mL}$. The licence (No. 0212, 18 February 2011) to use laboratory animals for the stem cell research and artificial tissue fabrication was issued by the Lithuanian Ethics Commission at the State Food and Veterinary Service.

\section{Results and Discussion}

In the following sections, we show the technology's state-of-the-art and implemented extensions demonstrated in this study: the entire sequence of making large area and volume 3D microporous structures (centimeters in footprint) permeable for cell culture with engineered micro-patterns for directionality control of cell growth and controlled surface roughness for optimal cell adhesion, migration and proliferation.

\subsection{FFF 3D Microprinting}

The synergetic approach of microfabrication-based technologies with cell biology lays foundation for the development of advanced in vitro diagnostic systems capable of analyzing cell cultures under 
physiologically relevant conditions [52]. Special interest is given to the so-called biofluidics, which covers microfluidic techniques for the development of 3D constructs and tissues [53]. For the mentioned purposes, FFF-based 3D printing is an attractive choice due to its simplicity and cost efficiency. The limitation of the technique in spatial resolution is given by the heating and extrusion nozzle. Special requirements using a polymer wire having a diameter much smaller than the conventional case $(0.05 \mathrm{~mm}$ in comparison to $0.4 \mathrm{~mm}$ ) were investigated. The approach was based on experimental and theoretical studies starting from conventional fused deposition modeling technology, where the study tested the swelling and cooling of the filament material during deposition [54]. Based on this, further studies will be targeting the implementation of smaller diameter nozzles, thus decreasing the FFF producible feature dimensions. Here, for the FFF step, we used the standard 0.4-mm-diameter logs to form 3D $\log$ /wood-pile structures (Figures 4 and 6).

\subsection{Characteristics of Light Filament-Assisted vs. Sharp Beam Focusing for 3D Microstructuring}

In this study, we have experimentally demonstrated that a liquid-assisted fabrication has several hereinafter mentioned advantages for laser beam delivery. The main factor is its the contribution as the media for femtosecond light pulse-generated filament formation via self-focusing and white light continuum generation, which allows homogeneous energy distribution along the beam and ensures efficient energy delivery required for rapid microfabrication. The light filament helps to avoid the precise matching of the focal plane to the sample's surface, as well as a $Z$ translation for the sample for $2 \mathrm{~mm}$ and more, depending on its dimensions. Additionally, light filamentation helps to remove the excess of accumulated heat- and ablation-generated microparticles, which stay on the sample as debris. In the studied case, for the femtosecond pulse-generated light filament formation and its efficient application for rapid fabrication at employed irradiation conditions, a 10-fold higher average power was used as compared to the sharp focusing case. Structuring efficiency in terms of area (volume) per time scaled with laser power almost linearly within the examined range, as the beam's peak power was exceeding the threshold of modification several times [47]). Hence, a higher power fs laser can be implemented to further increase the fabrication throughput. The only drawback was the need of sample submersion into water. FPF requires a water reservoir, and in this case, only 2.5D fabrication is possible. If curved surfaces have to be processed, then additional $Z$ axis positioning may become required. Furthermore, the absorption in water (liquid) cannot be neglected, as it introduces energy losses and evaporation, especially due to filamentation via self-focusing, usually accompanied by the white light continuum (WLC), which broadens the spectrum of irradiation. Employment of frequency-doubled (visible) wavelengths could be considered in future experiments towards targeted applications. Yet, for shorter wavelengths, self-actions would be increased, and the non-linear absorption would increase. Therefore, precise consideration of the irradiation wavelength, WLC, as well as material and liquid absorption have to be considered for each specific case. As a rule of thumb, photons with photon energy smaller than half of the host material bandgap are used for efficient WLC generation avoiding competing two photon absorption.

In Figure 6 grooves obtained using (a) 8-, (b) 1- and (c,d) 10-mm/s translation velocities, respectively, are shown. The applied power $P$ was $200 \mathrm{~mW}$. 
The microholes were created in PLA sheets, and woodpiles are shown in Figure 7. The laser fabrication parameters were as follows: in sharp focusing mode, the $v$ along the $Z$-axis was $0.5 \mathrm{~mm} / \mathrm{s}$ and $P=280 \mathrm{~mW}$, as for FPF, the samples were kept fixed at the same $Z$ and the power $P$ was set to $5 \mathrm{~W}$. Note, the surface around laser-treated locations had a reduced debris deposition due to the used water immersion.

Complex-shaped pieces can be successfully produced employing the FPF method, as shown in Figure 8. Functional micro-objects, such as micro-gears or arrow-shaped structures, could be used for applications in bio- and micro-mechanics and illustrate the capability of an arbitrary structuring. The FPF parameters were chosen as follows: velocity $v$ in the $X-Y$ plane was $100 \mathrm{~mm} / \mathrm{s}$. Three repetitive contour scans were used for the cutting and took 30 and $4 \mathrm{~s}$ for the gear and arrow, respectively.

Figure 8. SEM micrographs of FPF cut shapes: (a,c) bulk; (b,d) woodpile-scaffold type.

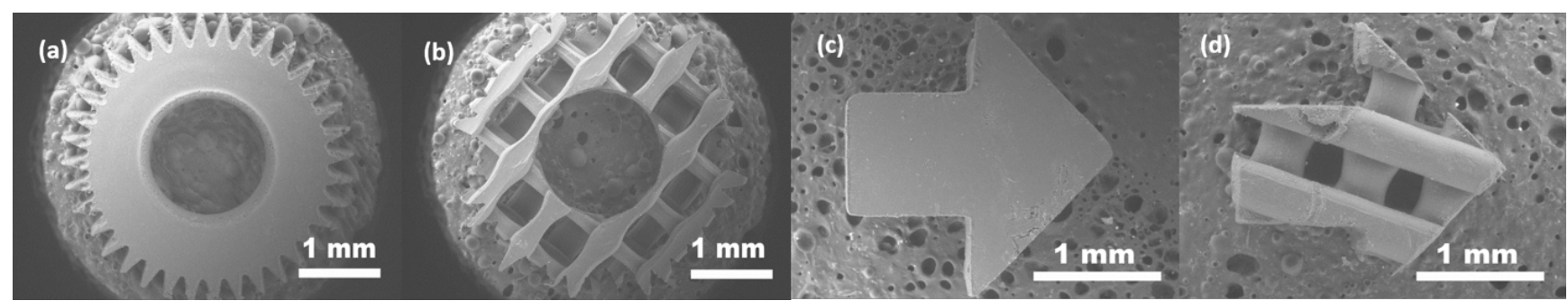

In the case of filament ablation, the ablated debris is contained in the surrounding water and does not latch on the processed sample. This is due to the formation of cavitation bubbles and strong debris ejection during collapse of the bubbles $[55,56]$.

The minimum obtained feature size was approximately $50 \mu \mathrm{m}$ using the outlined setup. However, the spatial resolution depends on the material chosen (and can vary approximately up to $30 \mu \mathrm{m}$ using the same setup). Smaller features are expected using higher NA focusing conditions and lower average laser power. Larger features are expected when using longer pulses lasers (they can vary if the pulses are bandwidth limited or chirped) and higher average laser power. The properties of the water are of negligible influence.

\subsection{Surface Wettability via Roughness: Acetone Bath}

Immersion of samples in acetone significantly increased their surface roughness at the micro- and nano-scale Figure 3. One minute of immersion generated micro-granulation of the PLA layer, and $8 \mathrm{~min}$ created a mesh structure. After keeping the samples immersed for a longer duration, the objects would show signs of melt and delaminate in a layer-by-layer manner. After drying the acetone, one could find single particles with dimensions reaching up to $16 \mu \mathrm{m}$. For a preliminary qualitative inspection of the improvement of hydrophilic properties, the sheets of PLA were immersed in an acetone bath for $15 \mathrm{~min}$. After drying, a 100- $\mu \mathrm{L}$ droplet was drop cast onto the surface, and it spread, covering an area approximately equal to $\sim 78 \mathrm{~mm}^{2}$. In comparison, a non-treated surface corresponded to a $7 \mathrm{~mm}^{2}$ covered area for the same $100-\mu \mathrm{L}$ droplet. This indicates that the wetting properties are significantly improved, meaning that PLA can be easily modified for the desired hydrophilicity required for cell adhesion. 


\subsection{Cell Growth on 3D PLA Scaffolds}

In an alive organism, the extra cellular matrix (ECM) strongly influences cell behavior. The fabricated scaffolds imitate the native ECM and have an impact on the cells by biological, chemical and physical cues from the ECM. Therefore, subtle changes in the scaffold architecture determine cellular fate [57]. The pores are one of the key elements in the scaffold topography. Their size has a very important impact on cell behavior; however, there is a dual relationship between them [58]. There has been reports that cells grown on micro-roughened surfaces were stimulated towards differentiation [59]. Increased surface area, provided by small pores, may have a beneficial effect on cell adhesion. Nevertheless, improved cellular infiltration and migration, facilitated by larger pores, outweighs this effect. An assortment of small and large pores seems to provide the most benefit for cell growth and proliferation optimization [60]. The interplay between cells and scaffolds (their properties and composition) has shown to influence integrin-ligand interactions, thus affecting cell morphology and differentiation [61]. The local formation of tissue depends on the interaction between cells and the engineered component, which depends on the surface chemistry and topography of the scaffold [62]. Figure 8 shows the versatility of the high aspect ratio structuring of log/wood-pile construction. Together with hole drilling by percussive irradiation, a volume fraction of polymer can be engineered for the required mechanical properties (the effective Young modulus) [63], making the scaffold compatible with its in vivo components in the final tissue. For tissue engineering, special attention is given to the cells. Different putative sources of adult stem cells have been identified in living organisms [64]. Some of them include more than one type of progenitor cells. An important consideration is the delivery of autologous cells ex vivo, which are harvested directly from the individual undergoing surgical procedure. The use of such cells for tissue construction is acceptable in biomedical and ethical aspects. In our experiments, primary adult rabbit skeletal muscle-derived myogenic cells were used. A rabbit model is convenient for artificial tissue construction and transplantation of such a construct into an organism.

The scaffolds used in this work were 3D-printed out of PLA. Cell proliferation, viability and differentiation trends were studied. As evident in Figure 9, myogenic cells grown on the PLA scaffolds were alive, recognizable viable after staining with acridine orange and ethidium bromide; the green colour indicates viable cells. Fluorescence microscope images show that the myogenic progenitor cells fully-filled and homogeneously colonized scaffolds. It is known that the cell response to surface roughness is different depending on the cell type: for larger cells, the surface roughness could be correspondingly greater [65]. We observed (the data are not presented here) that the muscle-derived myogenic progenitor cells differentiated into osteoblasts much more intensively on the porous scaffolds. These initial results need further coherent investigation in detail, which is out of scope of this paper. Similar research has been carried out with the endothelium-derived progenitor cells; however, a similar effect was not observed. These cells were smaller than myogenic cells, and the interaction with the topography of the tested scaffold was less noticeable. Material surface roughness has a direct influence on cellular morphology, proliferation and phenotype [66]. For instance, primary rat osteoblasts had higher proliferation, an elevated alkaline phosphatase (ALP) activity and an osteocalcin expression on the rough surface (the min-max span of the height was $0.81 \mu \mathrm{m}$ ) in comparison with a smooth one [67]. The studies have demonstrated the importance of scaffold micro-architecture, cell type and 
the application the fabricated scaffold. Additional micro-/nano-structuring technology that can change the surface roughness has potential applications and an evident biological impact on the construction of artificial tissue. Recently, it was demonstrated that bactericidal properties are related to the mechanical properties of surface nano-micro structure in the case of black silicon [68].

Figure 9. The SEM (a,d), light (b,e) and fluorescence microscope images (c,f) of the 3D printed scaffolds and myogenic cells grown on them: (top) 2.5D full-filled; (bottom) 3D microporous); in (c,f), cells are grown for $24 \mathrm{~h}$ and stained by an acridine orange-ethidium bromide mixture. Living cells are stained green, and dead cells are stained orange. The surface of the material is evidently biocompatible.

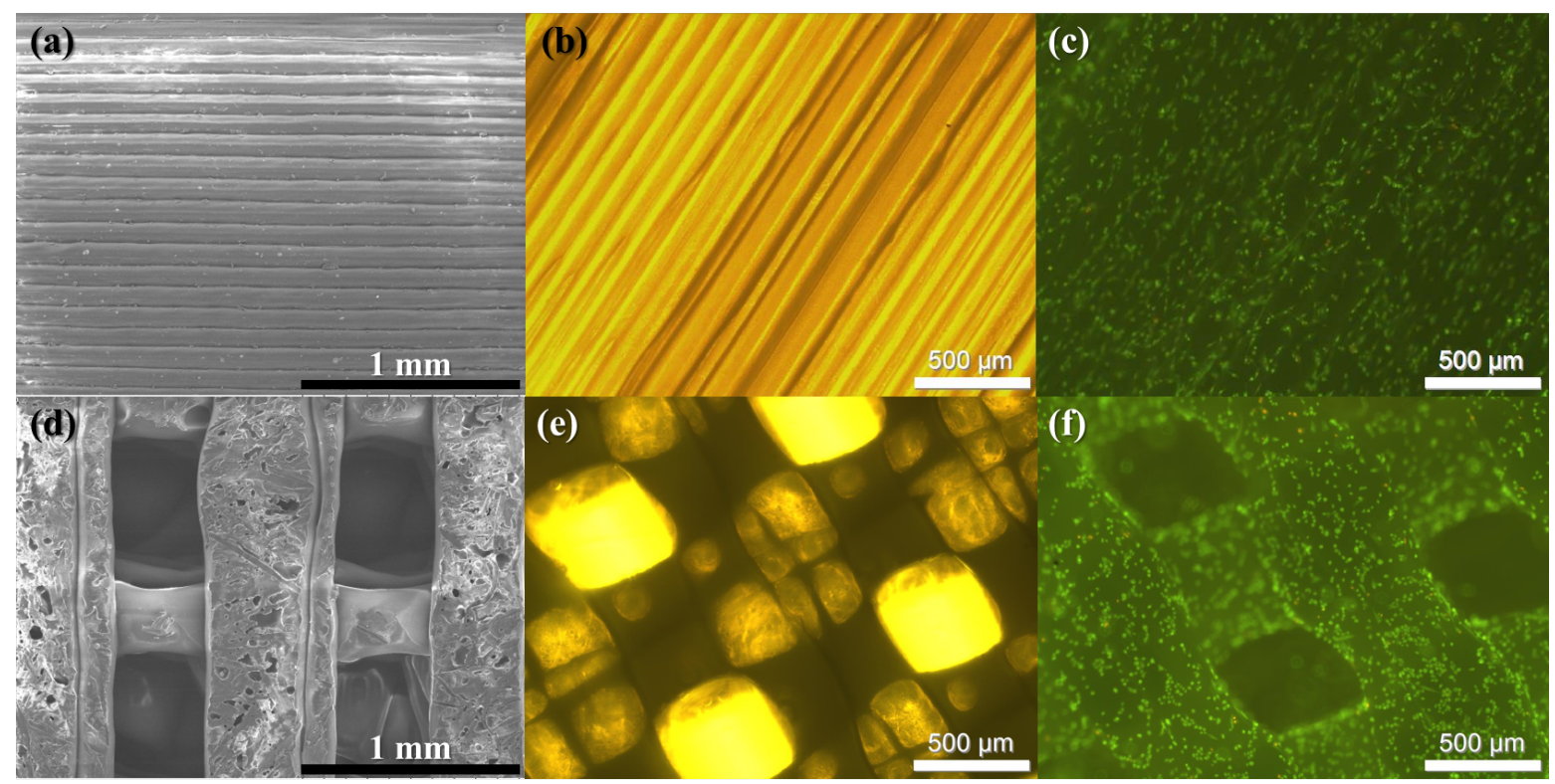

\subsection{Outlook}

The proposed method combining FFF and DLW is not limited to only being employed sequentially as an additive followed by subtractive manufacturing (AM and SM, respectively). Highly porous 3D scaffolds can be seeded with cells by means of another DLW method: laser-induced forward transfer (LIFT). In this laser printing approach, a propulsive force, resulting from a laser-induced shock wave, is used to propel individual cells or cell groups from a donor substrate towards the receiver substrate. It was demonstrated that a combination of DLW lithography and LIFT can provide a route for realizing 3D multicellular tissue constructs and artificial ECM engineered at the microscale [69]. This shows the potential of FFF scaffolds to be "colonized" via another laser printing approach. Moreover, ultrashort laser pulses were demonstrated to be the most efficient means to deliver propulsion in LIFT [70]. Further research focused on investigating the limits of FFF employing smaller diameter nozzles, as well as applying materials with incorporated biologically and mechanically active components, such as nHA (nanoHydroxyApatite; beneficial for the increase of mechanical strength, a natural chemical compound and improving the biological properties [71]), is strongly required.

The micro-porosity of 3D patterns are important for the formation of blood vessels in the tissue, one of the most challenging and least understood steps for grafting and implantation of the artificial tissue. 
Fabrication of such constructs can be realized via the DLW-AM technique, allowing micro-precise sculpting of the whole structure [72]. DLW-SM processing of vessels is also possible [39,73]; however, the facilitation of their proliferation naturally by the pattern is the final goal. This can be achieved by preparing the cross-flow open structures as generalized by the construction law of design and evolution in nature [74]. The patterns that facilitates cross flows are those that develops best, e.g., channel diameters should scale according to certain factors at the bifurcation/coalescence points by which the overall flow through the architecture is facilitated. The Hess-Murray design rule for diameters is $D_{1} / D_{2}=2^{1 / 3}$. The initial porosity of the artificial scaffold should be chosen with this in mind, as blood vessels will proliferate in the 3D structure.

Lastly, although dramatic progress in commercially available micro-stereolithography setups regarding price drop and functionality increase is evident [75], FFF combined with DLW lithography approaches have the potential to be unique in terms of combining composite materials in the microscale for 3D scaffold fabrication. This DLW functionalization of surfaces are shown to be important in biofilm formation and can guide bacterial infections [76,77]. The pattern of micro-furrows on the surface can guide faster or slower cell propagation on complex 3D surfaces and facilitate faster or retarded colonization of the surface, as required for a particular application. For the formation of neuronal networks, the ordering of micro/nano-grooves is expected to have a deterministic role.

The 3D ordered patterns of sub-mm logs form a photonic crystal for $\mathrm{THz}$ radiation and form strong reflection at a particular wavelength. One could foresee a possibility to use non-ionising $\mathrm{THz}$ radiation to monitor cell coverage of the scaffold.

\section{Conclusions}

In this study, we proposed a combination of FFF 3D printing and DLW ablation for efficient 3D microfabrication of biocompatible and biodegradable polymer scaffolds of PLA. One of the main fields of potential applications-tissue engineering-was reviewed. The main goal of this research was to produce artificial scaffolds with micro-features out of PLA, which would be suitable for stem cell growing studies and regenerative medicine applications.

The 3D patterns were realized using a thermal extrusion 3D printer, which is a simple, low-cost tabletop device enabling rapid materialization of CAD models in plastics and surface finish with a sophisticated femtosecond laser microfabrication setup. Centimeter-scale microporous (pore size varying from 100 to $400 \mu \mathrm{m}$ ) woodpile scaffolds via thermal extrusion were successfully printed without sacrificial nor support structures required and can be used directly. Their structure geometry from macroto micro-scales were finely tuned by combining 3D printing parameters and femtosecond laser ablation employing sharp and filament focusing. 3D printed PLA log-/wood-piles were structured via laser ablation by making 5-10 $\mu \mathrm{m}$ width and 10-100 $\mu \mathrm{m}$ deep grooves, as well as 30-130 $\mu \mathrm{m}$ in diameter and 170-600 $\mu \mathrm{m}$ deep holes (aspect ratio of 4 to 5). It is shown in this work that much deeper and smoother holes could be made with light filament-assisted ablation. Additionally, PLA surface roughness at the nanoscale can be increased by simply immersing the objects into an acetone bath.

The 3D printed PLA scaffolds were seeded with primary myogenic stem cells, and the results showed good biocompatibility. The creation of additional microstructure and an increase of surface roughness 
is an important issue in connection with the cell type used and with the intention of artificial tissue construction. Such 3D objects can be used for cell growth or as biodegradable implants in tissue engineering, as well as integrated micromechanic or microfluidic devices.

\section{Acknowledgments}

The research leading to these results has received funding from LASERLAB-EUROPE (Grant Agreement No. 284464, EC's Seventh Framework Programme) and the European Social Fund under National Integrated Programme Biotechnology and Biopharmacy, Grant VP1-3.1-SMM-08-K01-005.

\section{Author Contributions}

Mangirdas Malinauskas designed the concept and organized the study. Sima Rekštytè performed the DLW-AM manufacturing. Laurynas Lukoševičius and Simas Butkus did the 3DP and DLW-SM manufacturing, as well as SEM characterization of the samples. Evaldas Balčiūnas prepared the sketches. Milda Pečiukaitytė, Daiva Baltriukienè and Virginija Bukelskienè performed the cell growth experiments and interpreted them. Arūnas Butkevičius and Povilas Kucevičius provided the 3D printer and information regarding the technology. Vygandas Rutkūnas defined the tissue engineering requirements for the materials and artificial 3D scaffoldings. All of the authors wrote the whole manuscript.

\section{Conflicts of Interest}

The authors declare no conflict of interest. The presented information can be freely used for educational, academic or commercial purposes for the sake of the improvement of humanity's well being.

\section{References}

1. Lithuanian Laser Association Home Page. Available online: http://www.ltoptics.org/ (accessed on 27 July 2014).

2. 3D Printing Industry Home Page. Available online: http://3dprintingindustry.com/ (accessed on 27 July 2014).

3. Zhang, Y.L.; Chen, Q.D.; Xia, H.; Sun, H.B. Designable 3D nanofabrication by femtosecond laser direct writing. Nano Today 2010, 5, 435-448.

4. Malinauskas, M.; Farsari, M.; Piskarskas, A.; Juodkazis, S. Ultrafast laser nanostructuring of photopolymers: A decade of advances. Phys. Rep. 2013, 533, 1-31.

5. Sugioka, K.; Cheng, Y. Ultrafast lasers-reliable tools for advanced materials processing. Light Sci. Appl. 2014, 3, e149.

6. Schell, A.; Kaschke, J.; Fischer, J.; Henze, R.; Wolters, J.; Wegener, M.; Benson, O. Three-dimensional quantum photonic elements based on single nitrogen vacancy-centres in laser-written microstructures. Sci. Rep. 2012, 3, 1577.

7. Turner, M.; Saba, M.; Zhang, Q.; Cumming, B.; Schroder-Turk, G.; Gu, M. Miniature chiral beamsplitter based on gyroid photonic crystals. Nat. Photon. 2013, 7, 801-805. 
8. Žukauskas, A.; Malinauskas, M.; Brasselet, E. Monolithic generators of pseudo-nondiffracting optical vortex beams at the microscale. Appl. Phys. Lett. 2013, 103, 181122.

9. Rajamanickam, V.; Ferrara, L.; Toma, A.; Zaccaria, R.P.; Das, G.; Fabrizio, E.D.; Liberale, C. Suitable photo-resists for two-photon polymerization using femtosecond fiber lasers. Microelectron. Eng. 2014, 121, 135-138.

10. Weiss, T.; Hildebrand, G.; Schade, R.; Liefeith, K. Two-Photon polymerization for microfabrication of three-dimensional scaffolds for tissue engineering application. Eng. Life Sci. 2009, 9, 384-390.

11. Raimondi, M.; Nava, M.; Eaton, S.; Bernasconi, A.; Vishnubhatla, K.; Cerullo, G.; Osellame, R. Optimization of Femtosecond Laser Polymerized Structural Niches to Control Mesenchymal Stromal Cell Fate in Culture. Micromachines 2014, 5, 341-358.

12. Chen, X.; Su, Y.D.; Ajeti, V.; Chen, S.J.; Campagnola, P. Cell Adhesion on Micro-Structured Fibronectin Gradients Fabricated by Multiphoton Excited Photochemistry. Cellular Molecular Bioeng. 2012, 5, 307-319.

13. Spivey, E.; Ritschdorff, E.; Connell, J.; McLennon, C.; Schmidt, C.; Shear, J. Multiphoton Lithography of Unconstrained Three-Dimensional Protein Microstructures. Adv. Func. Mater. 2013, 23, 333-339.

14. Kufelt, O.; El-Tamer, A.; Sehring, C.; Schlie-Wolter, S.; Chichkov, B. Hyaluronic Acid Based Materials for Scaffolding via Two-Photon Polymerization. Biomacromolecules 2014, 15, 650-659.

15. Dawood, F.; Qin, S.; Li, L.; Lina, E.; Fourkas, J. Simultaneous microscale optical manipulation, fabrication and immobilisation in aqueous media. Chem. Sci. 2012, 3, 2449-2456.

16. Klein, F.; Richter, B.; Striebel, T.; Franz, C.; von Freymann, G.; Wegener, M.; Bastmeyer, M. Two-Component Polymer Scaffolds for Controlled Three-Dimensional Cell Culture. Adv. Mat. 2011, 23, 1341-1345.

17. Rekštytė, S.; Kaziulionytė, E.; Balčiūnas, E.; Kaškelytè, D.; Malinauskas, M. Direct Laser Fabrication of Composite Material 3D Microstructured Scaffolds. J. Laser Micro/Nanoeng. 2014, 9, 25-30.

18. Danilevičius, P.; Rekštytè, S.; Balčiūnas, E.; Kraniauskas, A.; Jarašienè, R.; Širmenis, R.; Baltriukienè, D.; Bukelskienė, V.; Gadonas, R.; Malinauskas, M. Micro-structured polymer scaffolds fabricated by direct laser writing for tissue engineering. J. Biomed. Opt. 2012, $17,081405$.

19. Torgersen, J.; Qin, X.H.; Li, Z.; Ovsianikov, A.; Liska, R.; Stampfl, J. Hydrogels for Two-Photon Polymerization: A Toolbox for Mimicking the Extracellular Matrix. Adv. Func. Mat. 2013, 23, 4542-4554.

20. Ovsianikov, A.; Muhleder, S.; Torgersen, J.; Li, Z.; Qin, X.H.; Vlierberghe, S.; Dubruel, P.; Holnthoner, W.; Redl, H.; Liska, R.; Stampfl, J. Laser Photofabrication of Cell-Containing Hydrogel Constructs. Langmuir 2014, 30, 3787-3794.

21. Malinauskas, M.; Baltriukienè, D.; Kraniauskas, A.; Danilevičius, P.; Jarašienė, R.; Širmenis, R.; Žukauskas, A.; Balčiūnas, E.; Purlys, V.; Gadonas, R.; Bukelskienè, V.; Sirvydis, V.; Piskarskas, A. In vitro and in vivo biocompatibility study on laser 3D microstructurable polymers. Appl. Phys. A 2012, 108, 751-759. 
22. Žukauskas, A.; Batavičiūtè, G.; Ščiuka, M.; Jukna, T.; Melninkaitis, A.; Malinauskas, M. Characterization of photopolymers used in laser 3D micro/nanolithography bymeans of laser-induced damage threshold (LIDT). Opt. Mat. Express 2014, 4, 1601-1616.

23. Gittard, S.; Nguyen, A.; Obata, K.; Koroleva, A.; Narayan, R.; Chichkov, B. Fabrication of microscale medical devices by two-photon polymerization with multiple foci via a spatial light modulator. Biomed. Opt. Express 2011, 2, 3167-3178.

24. Stankevičius, E.; Gertus, T.; Rutkauskas, M.; Gedvilas, M.; Račiukaitis, G.; Gadonas, R.; Smilgevičius, V.; Malinauskas, M. Fabrication of micro-tube arrays in photopolymer SZ2080 by using three different methods of a direct laser polymerization technique. J. Micromech. Microeng. 2012, 22, 065022.

25. Beke, S.; Barenghi, R.; Farkas, B.; Romano, I.; Korosic, L.; Scaglione, S.; Brandi, F. Improved cell activity on biodegradable photopolymer scaffolds using titanate nanotube coatings. Mat. Sci. Eng. C 2014, 44, 38-43.

26. Beke, S.; Anjum, F.; Ceseracciu, L.; Romano, I.; Athanassiou, A.; Diaspro, A.; Brandi, F. Rapid fabrication of rigid biodegradable scaffolds by excimer laser mask projection technique: A comparison between 248 and 308 nm. Laser Phys. 2013, 23, 035602.

27. Buividas, R.; Rekštyte, S.; Malinauskas, M.; Juodkazis, S. Nano-groove and 3D fabrication by controlled avalanche using femtosecond laser pulses. Opt. Mater. Express 2013, 3, 1674-1686.

28. Rekštytė, S.; Malinauskas, M.; Juodkazis, S. Three-dimensional laser micro-sculpturing of silicone: Towards bio-compatible scaffolds. Opt. Express 2013, 21, 17028-17041.

29. Williams, J.; Adewunmi, A.; Schek, R.; Flanagan, C.; Krebsbach, P.H.; Feinberg, S.; Hollister, S.; Das, S. Bone tissue engineering using polycaprolactone scaffolds fabricated via selective laser sintering. Biomaterials 2005, 26, 4817-4827.

30. Yadroitsev, I.; Thivillon, L.; Bertrand, P.; Smurov, I. Strategy of manufacturing components with designed internal structure by selective laser melting of metallic powder. Appl. Surf. Sci. 2007, 254, 980-983.

31. Heinl, P.; Rottmair, A.; Korner, C.; Singer, R. Cellular Titanium by Selective Electron Beam Melting. Adv. Eng. Mat. 2007, 9, 360-364.

32. Harrysson, O.; Cansizoglu, O.; Marcellin-Little, D.; Cormier, D.; West, H. Direct metal fabrication of titanium implants with tailored materials and mechanical properties using electron beam melting technology. Mat. Sci. Eng. C 2008, 28, 366-373.

33. Schleifenbaum, H.; Meiners, W.; Wissenbach, K.; Hinke, C. Individualized production by means of high power Selective Laser Melting. CIRP J. Manuf. Sci. Technol. 2010, 2, 161-169.

34. Hutmacher, D.W. Scaffolds in tissue engineering bone and cartilage. Biomaterials 2000, 21, 2529-2543.

35. Chastek, T.; Wadajkar, A.; Nguyen, K.; Hudson, S.; Chastek, T. Polyglycol-templated synthesis of poly(N-isopropyl acrylamide) microgels with improved biocompatibility. Colloid Polym. Sci. 2010, 288, 105-114.

36. Ferraro, P.; Coppola, S.; Grilli, S.; Paturzo, M.; Vespini, V. Dispensing nano-pico droplets and liquid patterning by pyroelectrodynamic shooting. Nat. Nanotechnol. 2010, 5, 429-435. 
37. Knoll, A.W.; Zientek, M.; Cheong, L.; Rawlings, C.; Paul, P.; Holzner, F.; Hedrick, J.; Coady, D.; Allen, R.; Durig, U. Closed-loop high-speed 3D thermal probe nanolithography. SPIE Proc. 2014, 9049, 90490B.

38. RepRap. Available online: http://reprap.org/wiki/Fused_filament_fabrication (accessed on 27 July 2014).

39. Wang, H.W.; Cheng, C.W.; Li, C.W.; Chang, H.W.; Wu, P.H.; Wang, G.J. Fabrication of pillared PLGA microvessel scaffold using femtosecond laser ablation. Int. J. Nanomed. 2012, 7, 1865-1873.

40. Danilevicius, P.; Georgiadi, L.; Pateman, C.; Claeyssens, F.; Chatzinikolaidou, M.; Farsari, M. The effect of porosity on cell ingrowth into accurately defined, laser-made,polylactide-based 3D scaffolds. Appl. Surf. Sci. 2014, doi:10.1016/j.apsusc.2014.06.012.

41. Melissinaki, V.; Gill, A.; Ortega, I.; Vamvakaki, M.; Ranella, A.; Haycock, J.; Fotakis, C.; Farsari, M.; Claeyssens, F. Direct laser writing of 3D scaffolds for neural tissue engineering applications. Biofabrication 2011, 3, 045005.

42. Van Manen, E.; Zhang, W.; Walboomers, X.; Vazquez, B.; Yang, F.; Ji, W.; Yu, N.; Spear, D.; Jansen, J.; Yelick, P. The influence of electrospun fibre scaffold orientation and nano-hydroxyapatite content on the development of tooth bud stem cells in vitro. Odontology 2014, 102, 14-21.

43. Ivanova, O.; Williams, C.; Campbell, T. Additive manufacturing (AM) and nanotechnology: Promises and challenges. Rapid Prototyp. J. 2013, 19, 353-364.

44. Xiong, W.; Zhou, Y.; He, X.; Gao, Y.; Mahjouri-Samani, M.; Jiang, L.; Baldacchini, T.; $\mathrm{Lu}, \mathrm{Y}$. Simultaneous additive and subtractive three-dimensional nanofabrication using integrated two-photon polymerization and multiphoton ablation. Light Sci. Appl. 2012, 1, e6.

45. Eschenbaum, C.; Grossmann, D.; Dopf, K.; Kettlitz, S.; Bocksrocker, T.; Valouch, S.; Lemmer, U. Hybrid lithography: Combining UV-exposure and two photon direct laser writing. Opt. Express 2013, 21, 29921-29926.

46. Hengsbach, S.; Lantada, A. Rapid prototyping of multi-scale biomedical microdevices by combining additive manufacturing technologies. Biomed. Microdevices 2014, 16, 617-627.

47. Butkus, S.; Gaižauskas, E.; Paipulas, D.; Viburys, Z.; Kaškelytè, D.; Barkauskas, M.; Alesenkov, A.; Sirutkaitis, V. Rapid microfabrication of transparent materials using filamented femtosecond laser pulses. Appl. Phys. A 2014, 114, 81-90.

48. Juodkazis, S.; Misawa, H.; Louchev, O.; Kitamura, K. Femtosecond laser ablation of chalcogenide glass: Explosive formation of nano-fibres against thermo-capillary growth of micro-spheres. Nanotechnology 2006, 17, 4802-4805.

49. Tan, D.; Li, Y.; Qi, F.; Yang, H.; Gong, Q.; Dong, X.; Duan, X. Reduction in feature size of two-photon polymerization using SCR500. Appl. Phys. Lett. 2007, 90, 071106.

50. Malinauskas, M.; Bičkauskaitè, G.; Rutkauskas, M.; Paipulas, D.; Purlys, V.; Gadonas, R. Self-polymerization of nano-fibres and nano-membranes induced by two-photon absorbtion. Lith. J. Phys. 2010, 50, 135-140. 
51. Minardi, S.; Majus, D.; Gopal, A.; Tamošauskas, G.; Milian, C.; Couairon, A.; Pertsch, T.; Dubietis, A. Energy deposition dynamics of femtosecond pulses in water. ArXiv E-Prints 2014, arXiv:1405.5378.

52. Ertl, P.; Sticker, D.; Charwat, V.; Kasper, C.; Lepperdinger, G. Lab-on-a-chip technologies for stem cell analysis. Trends Biotechnol. 2014, 32, 245-253.

53. Hasan, A.; Paul, A.; Vrana, N.; Zhao, X.; Memic, A.; Hwang, Y.S.; Dokmeci, M.; Khademhosseini, A. Microfluidic techniques for development of 3D vascularized tissue. Biomaterials 2014, 35, 7308-7325.

54. Monzon, M.; Gibson, I.; Benitez, A.; Lorenzo, L.; Hernandez, P.; Marrero, M. Process and material behavior modeling for a new design of micro-additive fused deposition. Int. J. Adv. Manuf. Tech. 2013, 67, 2717-2726.

55. Ohl, C.D.; Arora, M.; Dijkink, R.; Janve, V.; Lohse, D. Surface cleaning from laser-induced cavitation bubbles. Appl. Phys. Lett. 2006, 89, 074102.

56. Song, W.; Hong, M.; Lukyanchuk, B.; Chong, T. Laser-induced cavitation bubbles for cleaning of solid surfaces. J. Appl. Phys. 2003, 95, 2952-2956.

57. Hawkins, A.; Milbrandt, T.; Puleo, D.; Hilt, J. Composite hydrogel scaffolds with controlled pore opening via biodegradable hydrogel porogen degradation. J. Biomed. Mater. Res. A. 2014, 102, 400-412.

58. Murphy, C.; Haugh, M.; O'Brien, F. The effect of mean pore size on cell attachment, proliferation and migrationin collagen-glycosaminoglycan scaffolds for bone tissue engineering. Biomaterials 2010, 31, 461-466.

59. Simitzi, C.; Stratakis, E.; Fotakis, C.; Athanassakis, I.; Ranella, A. Microconical silicon structures influence NGF-induced PC12 cell morphology. J. Tissue Eng. Regen. Med. 2014, doi:10.1002/term.1853.

60. Murphy, C.; Haugh, M.; O'Brien, F. The effect of mean pore size on cell attachment, proliferation and migration in collagen-glycosaminoglycan scaffolds for bone tissue engineering. Biomaterials 2010, 31, 461-466.

61. Murphy, C.; O’Brien, F.; Little, D.; Schindeler, A. Cell-scaffold interactions in the bone tissue engineering triad. Eur. Cells Mater. 2013, 26, 24052425.

62. Nooeaid, P.; Salih, V.; Beier, J.; Boccaccin, A. Osteochondral tissue engineering: Scaffolds, stem cells and applications. J. Cell. Mol. Med. 2012, 16, 2247-2270.

63. Juodkazis, S.; Mizeikis, V.; Seet, K.; Misawa, H.; Wegst, U. Mechanical properties and tuning of three-dimensional polymeric photonic crystals. Appl. Phys. Lett. 2007, 91, 241904.

64. Wagers, A.; Weissman, I. Plasticity of Adult Stem Cells Review. Cell 2004, 116, 639-648.

65. Donoso, M.; Mendez-Vilas, A.; Bruque, J.; Gonzalez-Martin, M. On the relationship between common amplitude surface roughness parameters and surface area: Implications for the study of cell-material interactions. Int. Biodet. Biodegr. 2007, 59, 245-251.

66. Chang, H.; Wang, Y. Cell Responses to Surface and Architecture of Tissue Engineering Scaffolds. In Regenerative Medicine and Tissue Engineering_Cells and Biomaterials; Eberli, D., Ed.; InTech: Rijeka, Croatia, 2011; pp. 569-588. 
67. Hatano, K.; Inoue, H.; Kojo, T.; Tsujisawa, T.; Uchiyama, C.; Uchida, Y. Effect of Surface Roughness on Proliferation and Alkaline Phosphatase Expression of Rat Calvarial Cells Cultured on Polystyrene. Bone 1999, 25, 439-445.

68. Ivanova, E.; Hasan, J.; Webb, H.; Gervinskas, G.; Juodkazis, S.; Truong, V.; Wu, A.; Lamb, R.; Baulin, V.; Watson, G.; Watson, J.; Mainwaring, D.; Crawford, R. Bactericidal activity of black silicon. Nat. Commun. 2013, 4, 2838.

69. Ovsianikov, A.; Gruene, M.; Pflaum, M.; Koch, L.; Maiorana, F.; Wilhelmi, M.; Haverich, A.; Chichkov, B. Laser printing of cells into 3D scaffolds. Biofabrication 2010, 2, 014104.

70. Hallo, L.; Mezel, C.; Bourgeade, A.; Hebert, D.; Gamaly, E.; Juodkazis, S. Laser-matter interaction in transparent materials: Confined microexplosion and jet formation. In Extreme Photonics and Applications, NATO Science for Peace and Security Series B: Physics and Biophysics; Springer: Heidelberg, Germany, 2010; pp. 121-146.

71. Wei, G.; Ma, P. Structure and properties of nano-hydroxyapatite/polymer composite scaffolds for bone tissue engineering. Biomaterials 2004, 25, 4749-4757.

72. Galanopoulos, S.; Chatzidai, N.; Melissinaki, V.; Selimis, A.; Schizas, C.; Farsari, M.; Karalekas, D. Design, fabrication and computational characterization of a 3D micro-valve built by multi-photon polymerization. Micromachines 2014, 5, 505-514.

73. Juodkazis, S. Writing 3D patterns of microvessels. Int. J. Nanomedicine 2012, 7, 3701-3702.

74. Bejan, A.; Lorente, S. Constructal law of design and evolution: Physics, biology, technology, and society. J. Appl. Phys. 2013, 113, 151301.

75. Comina, G.; Suska, A.; Filippini, D. PDMS lab-on-a-chip fabrication using 3D printed templates. Lab Chip 2014, 14, 424-430.

76. Gloag, E.; Javed, M.; Wang, H.; Gee, M.; Wade, S.; Turnbull, L.; Whitchurch, C. Stigmergy: A key driver of self-organization in bacterial biofilms. Commun. Integr. Biol. 2013, 6, e27331.

77. Loo, C.; Lee, W.; Cavaliere, R.; Whitchurch, C.; Rohanizadeh, R. Superhydrophobic, Nanotextured Polyvinyl Chloride Films for Delaying Pseudomonas Aeruginosa Attachment to Intubation Tubes and Medical Plastics. Acta Biomater. 2012, 8, 1881-1890.

(c) 2014 by the authors; licensee MDPI, Basel, Switzerland. This article is an open access article distributed under the terms and conditions of the Creative Commons Attribution license (http://creativecommons.org/licenses/by/4.0/). 